\title{
Crystal structure of $\mathrm{Na}_{v} \mathrm{AP}$, an orthologue of the $\mathrm{NaChBac}$ voltage-gated sodium channel
}

\author{
Xu Zhang ${ }^{1,2,8}$, Wenlin Ren ${ }^{1,2,8}$, Paul DeCaen ${ }^{3,8}$, Chuangye Yan ${ }^{1}$, Xiao Tao ${ }^{4}$, Lin Tang ${ }^{5}$, \\ Jingjing Wang ${ }^{6}$, Kazuya Hasegawa $^{7}$, Takashi Kumasaka ${ }^{7}$, Jianhua $\mathrm{He}^{5}$, Jiawei Wang ${ }^{1}$, \\ David E. Clapham ${ }^{3}$, and Nieng Yan ${ }^{1,2,9}$ \\ ${ }^{1}$ State Key Laboratory of Bio-membrane and Membrane Biotechnology, Center for Structural \\ Biology, School of Life Sciences and School of Medicine, Beijing 100084, China \\ ${ }^{2}$ Tsinghua-Peking Center for Life Sciences, Tsinghua University, Beijing 100084, China \\ ${ }^{3} \mathrm{HHMI}$, Department of Cardiology, Children's Hospital Boston, Boston, MA 02115, Department of \\ Neurobiology, Harvard Medical School, Boston, MA 02115, USA \\ ${ }^{4}$ Laboratory of Molecular Neurobiology and Biophysics, Rockefeller University, Howard Hughes \\ Medical Institute, 1230 York Avenue, New York, NY 10065, USA \\ 5Shanghai Institute of Applied Physics, Chinese Academy of Sciences, 239 Zhangheng Road, \\ Shanghai 201204, China \\ ${ }^{6}$ State Key Laboratory of Drug Research, Shanghai Institute of Materia Medica, Chinese \\ Academy of Sciences, Shanghai 201203, China \\ 7Japan Synchrotron Radiation Research Institute (SPring-8), 1-1-1 Kouto, Sayo-cho, Sayo-gun, \\ Hyogo 679-5198, Japan
}

\section{Abstract}

\begin{abstract}
Voltage-gated sodium $\left(\mathrm{Na}_{\mathrm{v}}\right)$ channels are essential for the rapid depolarization of nerve and muscle ${ }^{1}$, and are important drug targets ${ }^{2}$. A family of bacterial $\mathrm{Na}_{\mathrm{v}}$ channels, exemplified by

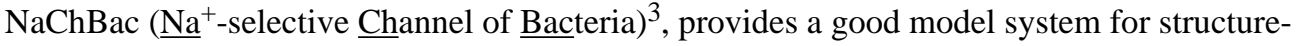
function analysis. Here we report the crystal structure of $\mathrm{Na}_{\mathrm{v}} \mathrm{AP}$, a $\mathrm{NaChBac}$ orthologue from marine bacteria alpha proteobacterium HIMB114, at $3.05 \AA$ resolution. The channel comprises an asymmetric tetramer. The carbonyl oxygen atoms of Thr178 and Leu179 constitute an inner site within the selectivity filter ( ${ }_{178} \mathrm{TLSSWE}_{183}$ ) where a $\mathrm{Ca}^{2+}$ can bind and resides in the crystal structure. The outer mouth of the $\mathrm{Na}^{+}$selectivity filter, defined by Ser181 and Glu183, is closed, as is the activation gate at the intracellular side of the pore. The voltage sensors adopt a depolarized conformation with all the gating charges exposing to the extracellular side. We hypothesize that $\mathrm{Na}_{\mathrm{v}} \mathrm{AP}$ is captured in an inactivated conformation. Comparison of $\mathrm{Na}_{\mathrm{v}} \mathrm{AP}$ with $\mathrm{Na}_{\mathrm{v}} \mathrm{Ab}^{4}$ reveals significant conformational rearrangements that may underlie the electromechanical coupling mechanism of voltage-gated channels.
\end{abstract}

$\mathrm{Na}_{\mathrm{v}}$ channels initiate and propagate action potentials in excitable cells ${ }^{1}$. Since $\mathrm{Na}_{\mathrm{v}}$ channels underlie a number of clinical disorders such as epileptic seizures and cardiac arrhythmias,

\footnotetext{
${ }^{9}$ To whom correspondence should be addressed. nyan@tsinghua.edu.cn.

${ }^{8}$ These authors contributed equally to this work.

Author Contributions X.Z., W.R., P.D., X.T., D.C., and N.Y. designed all experiments. X.Z., W.R., P.D., C.Y., X.T., L.T., J.W., K.H., T.K., J.H., and J.W. performed the experiments. X.Z., W.R., P.D., C.Y., X.T., J.W., D.C., and N.Y. analysed the data. X.Z., P.D., X.T., C.Y., J.W. and D.C. contributed to manuscript preparation. N.Y. wrote the manuscript.
}

Author Information The atomic coordinates of NaVAP have been deposited in the Protein Data Bank under accession code 4DXW. 
they are important drug targets ${ }^{2}$. Elucidation of the structures and functional mechanisms of $\mathrm{Na}_{\mathrm{v}}$ channels will shed light on fundamental ion channel mechanisms and facilitate potential clinical applications. The eukaryotic $\mathrm{Na}_{\mathrm{v}}$ channels are comprised of a pore-forming $\mathrm{a}$ subunit and auxiliary subunits 5 . It consists of one single polypeptide chain that is organized into four repeated domains $\left(\mathrm{D}_{\mathrm{I}}-\mathrm{D}_{\mathrm{IV}}\right)$ of six transmembrane-spanning (S1-S6) segments. The S5 and S6 segments from each domain form the pore region of the channel, which are flanked by four voltage sensing domains (VSDs) consisting of S1-S4. The VSD, a relatively independent structural entity ${ }^{6-9}$, provides the molecular basis for voltage sensing in voltagedependent channels and enzymes.

Essential for voltage-dependent gating, VSDs contain the gating charges ${ }^{10}$ embodied in a set of highly conserved positively charged residues occurring every three residues along the S4 segment. In $\mathrm{Kv}$ channels, approximately 12 gating charges per channel are transferred across the membrane from the cytosolic side to the extracellular side ${ }^{11,12}$. While multiple models of voltage sensor activation have been proposed, it is generally accepted that the outward translation of S4 segments is coupled to pore opening via the interactions between the S4S5 connecting helices and S6 segments ${ }^{7,8}$.

The activation mechanism is not fully understood. Even more bewildering is the intricate inactivation mechanism for voltage-gated channels. Fast inactivation or N-type inactivation, taking place on millisecond scale, is executed by a cytoplasmic moiety between repeats III and IV of $\mathrm{Na}_{\mathrm{v}}$ channels ${ }^{13}$, or by the $\mathrm{N}$-terminus of the Shaker $\mathrm{K}^{+}$channel ${ }^{14-16}$. Also during prolonged depolarization, slow or "C-type" inactivation ${ }^{17}$ is thought to result from a conformational change of the selectivity filter ${ }^{18,19}$.

The prokaryotic homologues of $\mathrm{Na}_{\mathrm{v}}$ channels, exemplified by $\mathrm{NaChBac}^{3}$, are homotetramers of 6-TM subunits. Interestingly, the sequence of $\mathrm{NaChBac}$ is closer to that of $\mathrm{Ca}_{\mathrm{v}}$ channels ${ }^{20}$. Thus, structural elucidation of $\mathrm{NaChBac}$ homologues is expected to provide insights into both $\mathrm{Na}_{\mathrm{v}}$ and $\mathrm{Ca}_{\mathrm{v}}$ channels. To promote a deeper mechanistic understanding of $\mathrm{Na}_{\mathrm{v}}$ channels, we determined the crystal structure of a $\mathrm{NaChBac}$ homologue, $\mathrm{Na}_{\mathrm{v}} \mathrm{AP}$ (Supplementary Fig. 1-5, Tables S1\&S2). During refinement of our structure, the atomic crystal structure of $\mathrm{Na}_{\mathrm{v}} \mathrm{Ab}$ was published ${ }^{4}$. Compared to $\mathrm{Na}_{\mathrm{v}} \mathrm{Ab}, \mathrm{Na}_{\mathrm{v}} \mathrm{AP}$ reveals a number of distinct and mechanistically informative structural features.

As in all the known structures of voltage-gated channels, the VSD of one protomer attaches to the pore-forming unit of the adjacent protomer (Fig. 1a). The activation gate formed by $\mathrm{S} 6$ of $\mathrm{Na}_{\mathrm{v}} \mathrm{AP}$ is closed, although Leu219, the residue that occludes the gate, is one helical turn above the functionally equivalent Met221 in $\mathrm{Na}_{\mathrm{v}} \mathrm{Ab}$ (Fig. 1b, right panel) ${ }^{4}$. Notably, the narrowest point along the pore is at Ser181, which together with Glu183 encloses the entrance to the selectivity filter vestibule (Fig. 1b, right panel). While the selectivity filter of $\mathrm{Na}_{\mathrm{v}} \mathrm{Ab}$ is open and may allow the conductance of hydrated $\mathrm{Na}^{+}$, that of $\mathrm{Na}_{\mathrm{v}} \mathrm{AP}$ is closed (Fig. 1c).

Both the pore domain and the VSDs of $\mathrm{Na}_{\mathrm{v}} \mathrm{AP}$ exhibit structural variations among the four protomers, resulting in an asymmetric tetramer. The selectivity filter of $\mathrm{Na}_{\mathrm{V}} \mathrm{AP}$ ${ }_{178} \mathrm{TLSSWE}_{183}$ ) connects $\mathrm{P} 1$ (corresponding to the P-helix in $\mathrm{K}^{+}$channel) and $\mathrm{P} 2$ helices (Fig. 2, Supplementary Fig. 6). The side groups of Ser180, Ser181, and Glu183, as well as the carbonyl oxygen atoms of Thr178 and Leu179 constitute the electronegative vestibule of the selectivity filter (Fig. 2a). The entrance to the selectivity filter is negatively charged owing to the side groups of Glu183. The side groups of Ser181 adopt distinctive conformations among the four protomers, leading to the asymmetry of the selectivity filter (Supplementary Fig. 6). 
Notably, two residues in the selectivity filter of $\left(\mathrm{Na}_{\mathrm{v}} \mathrm{AP}\right.$ Ser180/Glu183 vs. Glu178/Ser181 of $\mathrm{Na}_{\mathrm{v}} \mathrm{Ab}$ ) are swapped in the primary sequences. However, structural superimposition shows that the carboxylate groups of $\mathrm{Na}_{\mathrm{v}} \mathrm{AP}-\mathrm{Glu} 183$ in are positioned similarly to those of Glu178 in the adjacent protomer of $\mathrm{Na}_{\mathrm{v}} \mathrm{Ab}$ despite their distinct backbone locations (Fig. $2 b$ ). Therefore, $\mathrm{Na}_{\mathrm{v}} \mathrm{AP}-\mathrm{Glu} 183$ and $\mathrm{Na}_{\mathrm{v}} \mathrm{Ab}-\mathrm{Glu} 178$ appear to be functional equivalents. This structural observation provides a basis to begin to understand the function of the negatively charged residues in the eukaryotic $\mathrm{Na}_{\mathrm{v}}$ channels that seem to be located at different positions in the selectivity filter (Fig. 2b, left panel).

Like many other bacterial channels, $\mathrm{Na}_{\mathrm{v}} \mathrm{AP}$ did not yield measurable ion currents when heterologously expressed in insect or mammalian cell lines, or when expressed in E.coli BL21(DE3) purified, reconstituted into lipids (POPE:POPG 3:1 mass ratio) and fused into bilayers with lipid composition of either POPE:POPG (3:1 mass ratio) or DPhPC. In order to test the selectivity of the $\mathrm{Na}_{\mathrm{v}} \mathrm{AP}$ channel, we generated a chimera by replacing the selectivity filter of $\mathrm{NaChBac}$ with that of $\mathrm{Na}_{\mathrm{v}} \mathrm{AP}$ (Supplementary Fig. 7). The chimeric channel was $\mathrm{Na}^{+}$-selective when expressed in HEK-293 cells and measured under voltageclamp (Fig. 2c). Similar to observations with other NaChBac pore mutations ${ }^{21,22}$, the chimera's $\left(\mathrm{NaChBac} / \mathrm{Na}_{\mathrm{v}} \mathrm{AP}\right.$-filter) voltage dependence of activation was shifted $(+49 \mathrm{mV}$; Fig. 2d) with an altered rate of inactivation (1.6x increase; Fig. 2d). Similar to NaChBac, the chimera was blocked by the $\mathrm{Na}_{\mathrm{v}}$ channel antagonist, lidocaine, and the $\mathrm{Ca}_{\mathrm{v}}$ antagonist, nifedipine (Supplementary Fig. 7d), but remained insensitive to tetrodotoxin.

During structure refinement, a spherical electron density appeared in the selectivity filter (Supplementary Fig. 8a). We conclude that the electron density is from a calcium ion since: 1) addition of $100 \mathrm{mM} \mathrm{CaCl}_{2}$ was indispensible for obtaining well-diffracting crystals; 2) crystals were also obtained for proteins purified in solutions with $\mathrm{RbCl}$ instead of $\mathrm{NaCl}$, and diffracted X-rays at the high remote wavelength for $\mathrm{Rb}^{+}$. After structural refinement, no anomalous signal for $\mathrm{Rb}^{+}$was observed whereas the omit electron density persisted, suggesting that the electron density was from $\mathrm{Ca}^{2+}$.

When $\mathrm{Ca}^{2+}$ was built into the $3.05 \AA$ structure and further refined, the $2 \mathrm{Fo}-\mathrm{Fc}$ electron density at $1.5 \sigma$ had an elongated tail on the side of the ion facing the central cavity (Supplementary Fig. 8b). A water molecule was then built into the appendage that was approximately $2.4 \AA$ away from the ion, fulfilling the geometric restraint of the interaction between water and $\mathrm{Ca}^{2+}$ (Fig. 2e). The $\mathrm{Ca}^{2+}$ ion is caged by the eight carbonyl oxygen groups from Thr178 and Leu179. The distances between $\mathrm{Ca}^{2+}$ and the eight carbonyl oxygen atoms are in the range of 3.5 to $4.6 \AA$ (Fig. 2e). For direct coordination of a $\mathrm{Ca}^{2+}$ by carbonyl oxygen atoms, the distance is usually between $2.3-2.5 \AA^{23}$. The well-defined electron density suggests that the ion is properly stabilized and thus the $\mathrm{Ca}^{2+}$ should be in a fully, or mostly, hydrated state. However, there was no distinguishable electron density for the surrounding water molecules, perhaps due to the moderate resolution of the structure and/or the intrinsic motility of those water molecules. $\mathrm{Ca}^{2+}$ and $\mathrm{Na}^{+}$effective ionic radii are practically identical ( $1.00 \AA$ vs. $1.02 \AA$ ), but with the primary hydration shell the radii are $2.7 \AA$ for $\mathrm{Ca}^{2+}$ and $2.2 \AA$ for $\mathrm{Na}^{+}$, respectively ${ }^{24}$. The observation that the inner binding site of the selectivity filter is spacious enough to accommodate a hydrated $\mathrm{Ca}^{2+}$ or $\mathrm{Na}^{+}$thus provides structural evidence for the hypothesis that $\mathrm{Na}_{\mathrm{v}}$ channels allow the passage of mostly hydrated $\mathrm{Na}^{+25}$.

Since the chimera was impermeant to $\mathrm{Ca}^{2+}$ (Fig. 2c), we hypothesized that $\mathrm{Ca}^{2+}$ might block $\mathrm{Na}^{+}$permeation ${ }^{26}$. Indeed, the $\mathrm{Na}^{+}$currents from $\mathrm{NaChBac}$ and the chimera were substantially blocked by $\mathrm{mM}$ concentrations of extracellular $\mathrm{Ca}^{2+}$ and $\mu \mathrm{M}$ concentrations of $\mathrm{Cd}^{2+}$ (Fig. 2f). We speculate that divalent ions are able to enter the channel and occlude the pore at the Leu179/Thr178 site. 
Compared to the subtle conformational variations of the filter residues among the four protomers, the divergences of VSDs are more prominent, particularly for S3-S4 linkers (Fig. 3a, Supplementary Fig. 9). Unlike the VSDs of Kv channels, in which the C-terminal segment of S3 and the N-terminal half of S4 form a paddle-like structure ${ }^{6-8}$, the C-terminal fragments of $\mathrm{S} 3$ in both $\mathrm{Na}_{\mathrm{v}} \mathrm{AP}$ and $\mathrm{Na}_{\mathrm{v}} \mathrm{Ab}$ are unwound. We name the four $\mathrm{Na}_{\mathrm{v}} \mathrm{AP}$ protomers Mol A through Mol D. S3-S4 linkers in Mol A and C are not resolved, while those in Mol B and D show distinct conformations; neither is similar to that of $\mathrm{Na}_{\mathrm{v}} \mathrm{Ab}$. The flexibility of the S3-S4 linker may allow the movement of the S4 segment during voltage sensing.

Transmembrane segments S1 - S4 of the four VSDs can be superimposed with RMSD (root-mean-squared deviation) values within 0.9 Å over 71 to $81 \mathrm{Ca}$ atoms (Fig. 3b). Consistent with a $0 \mathrm{mV}$ field during crystallization, all four conserved Arg residues on the S4 segment point extracellularly, representing a depolarized ("up") conformation (Fig. 3b). The external negative clusters stabilize the gating charges through two invariant interactions: R4 interacts with Asp48 (known as anion 1or An1) on S2 and R3 is H-bonded to the carbonyl oxygen of Ile 90 on S3 (Fig. 3c). In addition to these invariant interactions, there are additional stabilizing contacts specific to individual VSDs. In Mol A, an extra H-bond is between R2 and the carbonyl oxygen of Asn25 on S1. In Mol B, R3 binds to An1. In Mol C, $\mathrm{R} 3$ is further H-bonded to the carbonyl oxygen of Ser88.

The structure of $\mathrm{Na}_{\mathrm{v}} \mathrm{AP}$ has a closed inner gate and VSDs in a depolarized (i.e. open) conformation. Similar features were described for $\mathrm{Na}_{\mathrm{v}} \mathrm{Ab}$, which was proposed to be in the pre-open conformation ${ }^{4}$. While the structure of $\mathrm{Na}_{\mathrm{v}} \mathrm{AP}$ may also represent a pre-open state, an alternative interpretation is that $\mathrm{Na}_{\mathrm{v}} \mathrm{AP}$ is in an inactivated state. The following lines of evidence support this speculation: 1) $\mathrm{NaChBac}$ homologues and $\mathrm{NaChBac} / \mathrm{Na}_{\mathrm{v}} \mathrm{AP}$-filter chimera undergo inactivation on a millisecond to second time scale (Fig. $2 \mathrm{~d}$ ) ${ }^{17}$ and since purification and crystallization of the proteins occurs over days at $0 \mathrm{mV}$, we assume this should favor complete inactivation of the channel; 2) There is little interaction between S4S5 connecting helices and S6 segments (Fig. 3a), indicating a loss of coupling between the voltage sensor and the inner gate. Furthermore, the structure of $\mathrm{Na}_{\mathrm{v}} \mathrm{AP}$ is consistent with a possible form of inactivation discussed by Schmidt et al to account for the gating properties of $\mathrm{KvAP}^{27}$; when S4-S5 linkers release their constriction of the S6 helices, the inner gate may close even if the VSDs are still in the up conformation; 3) In both $\mathrm{Na}_{\mathrm{v}}$ and Shaker $\mathrm{K}$ channels, mutagenesis analyses suggested that the selectivity filter residues are involved in C-type inactivation ${ }^{17,19}$. In rat $\mathrm{Na}_{\mathrm{v}} 1.4$, residues Glu403, Glu758, Asp1241, and Asp1532, which correspond to Glu183 in $\mathrm{Na}_{\mathrm{v}} \mathrm{AP}$ (Fig. 2b and Supplementary Fig. 1) are important for inactivation ${ }^{28}$. In our structure of $\mathrm{Na}_{\mathrm{v}} \mathrm{AP}, \mathrm{Glu} 183$ and Ser 181 collectively close the outer mouth to the selectivity filter (Fig. 1c), supporting the reported functional significance of the outer negative charges in the inactivation process. Based on the above analyses, we speculate that the structure of $\mathrm{Na}_{\mathrm{v}} \mathrm{AP}$ shown here represents an inactivated conformation.

Superposition of the pore domains of $\mathrm{Na}_{\mathrm{v}} \mathrm{AP}$ and $\mathrm{Na}_{\mathrm{v}} \mathrm{Ab}$ reveal prominent conformational changes of the VSDs. Viewed from the cytoplasm, the VSDs of $\mathrm{Na}_{\mathrm{v}} \mathrm{AP}$ are rotated counterclockwise around the pore axis by $\sim 30^{\circ}$ and the relative positions of the VSDs in $\mathrm{Na}_{\mathrm{v}} \mathrm{AP}$ are more like those in the depolarized and open conformation of Kv1.2 ${ }^{7}$ (Fig. 4a). When the individual VSDs of $\mathrm{Na}_{\mathrm{v}} \mathrm{AP}$ and $\mathrm{Na}_{\mathrm{v}} \mathrm{Ab}$ were compared by superimposing the S4-S5 linkers, (Supplementary Fig. 10a), the VSDs diverge from each other suggesting that the VSD and S4-S5 linker do not move as a single unit. Asp48 (An1), Phe55, and Glu58 (An2) on the S2 segment constitute the charge transfer center (CTC) ${ }^{29}$ in $\mathrm{Na}_{\mathrm{v}} \mathrm{AP}$. Superimposing the VSDs of $\mathrm{Na}_{\mathrm{v}} \mathrm{AP}$ and $\mathrm{Na}_{\mathrm{v}} \mathrm{Ab}$ relative to the CTC, it is clear that the other transmembrane segments now are discordant, indicating a significant intra-domain rearrangement within the VSD (Supplementary Fig. 10b). 
Gating charges are transferred in response to a change in transmembrane voltage.

Superimposition of $\mathrm{Na}_{\mathrm{v}} \mathrm{AP}$ and $\mathrm{Na}_{\mathrm{v}} \mathrm{Ab}$ VSDs relative to the CTC unambiguously shows that there is a one helical turn shift of $\mathrm{Na}_{\mathrm{v}} \mathrm{AP}-\mathrm{S} 4$ toward the extracellular side (Fig. 4b). That is, for each $\mathrm{Na}_{\mathrm{v}} \mathrm{AP} \mathrm{VSD}$, one more charge is transferred than for each $\mathrm{Na}_{\mathrm{v}} \mathrm{Ab}$ VSD.

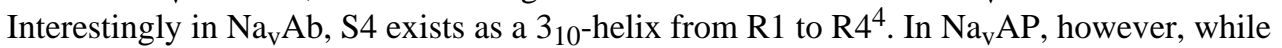
the segment from R3 to R4 forms a 310 -helix, the preceding segment is relaxed into an ahelix (Fig. 4b). We also compared the voltage sensors of $\mathrm{Na}_{\mathrm{v}} \mathrm{AP}$ to those of Kv1.2 and the paddle chimera, in which only the C-terminal halves of S4 segments containing R3 to R5

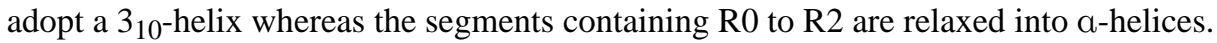
However, when the CTCs are superimposed, the relative positions of the gating charges, exemplified by $\mathrm{R} 4$ of $\mathrm{Na}_{\mathrm{v}} \mathrm{AP}$ are located between those of $\mathrm{Kv} 1.2$ and the paddle chimera (Fig. 4c).

The availability of voltage sensor structures with unique positions of the gating charges relative to the CTC provides evidence that supports our structure based animation of gating charge transfer (Fig. 4d and Supplementary movie S1).animation (Fig. 4d and

Supplementary movie S1). The movie illustrates how R3 and The movie illustrates how R3 and $\mathrm{R} 4$ are stabilized sequentially by An1 and An 2 to lower the energy barrier during the transfer of R4 across the occluding Phe residue. It also shows the secondary structure transition between $310^{-}$and a-helices, concurrent with the translational motion of S4 segment relative to CTC, which exemplifies the 'concertina effect' discussed for $\mathrm{Kv}$ channels ${ }^{8}$ and is consistent with the disulfide cross-linking experiments of $\mathrm{NaChBac}^{30}$. It is noteworthy that the flexibility of the S3-S4 linker may help lower the energy barrier during the motion and the secondary structural transition of S4 segment (Fig. 3a). The complementary studies of $\mathrm{Na}_{\mathrm{v}} \mathrm{AP}$ and $\mathrm{Na}_{\mathrm{v}} \mathrm{Ab}$ thus provide an important framework for future functional and mechanistic investigations of voltage-gated ion channels.

\section{Materials and methods}

\section{Protein preparation}

The cDNAs of NaChBac homologs, whose sequences were codon optimized for E.coli expression, were cloned into bacteria expression vectors and the recombinant proteins were over-expressed in E. coli BL21(DE3). After screening several dozens of homologs, only alpha proteobacterium $\mathrm{HIMB} 114\left(\mathrm{Na}_{\mathrm{v}} \mathrm{AP}\right)$ yielded crystals. The proteins from all homologs were purified without protease inhibitors, which we surmise helps in the selection of the most compact and stable targets ${ }^{31}$. The full-length $\mathrm{Na}_{\mathrm{v}} \mathrm{AP}$ was cloned into $\mathrm{pET} 21 \mathrm{~b}$ vector (Novagen). The $\mathrm{Na}_{\mathrm{v}} \mathrm{AP}$ mutants were generated using two-step PCR and were subcloned, overexpressed and purified in the same way as wild-type (WT) protein. Overexpression of $\mathrm{Na}_{\mathrm{V}} \mathrm{AP}$ was induced in $E$. coli BL21 (DE3) by $0.2 \mathrm{mM}$ isopropyl- $\beta$-D-thiogalactoside (IPTG) when the cell density reached $O . D_{600 \mathrm{~nm}} 1.5$. After growth at $30^{\circ} \mathrm{C}$ for $12 \mathrm{~h}$, the cells were harvested, resuspended in a buffer containing $25 \mathrm{mM}$ Tris- $\mathrm{HCl}, \mathrm{pH} 8.0$, and 150 $\mathrm{mM} \mathrm{NaCl}$, and disrupted by sonication. Cell debris was removed by centrifugation at 27,000 $g$ for $10 \mathrm{~min}$. The supernatant containing the membrane was collected and applied to ultracentrifugation at 150,000 $\mathrm{g}$ for $1 \mathrm{~h}$. The membrane fraction was collected and incubated with $1.6 \%(\mathrm{w} / \mathrm{v}) n$-dodecyl- $\beta$-D-maltopyranoside (DDM, Anatrace) for $2 \mathrm{~h}$ at $4{ }^{\circ} \mathrm{C}$. After an additional ultracentrifugation at $150,000 \mathrm{~g}$ for $30 \mathrm{~min}$, the supernatant was loaded to $\mathrm{Ni}^{2+}$ nitrilotriacetate affinity resin (Ni-NTA, Qiagen). Subsequently, the resin was rinsed $\times 3$ with $10 \mathrm{ml}$ buffer containing $25 \mathrm{mM}$ Tris- $\mathrm{HCl}, \mathrm{pH} 8.0,500 \mathrm{mM} \mathrm{NaCl}, 50 \mathrm{mM}$ imidazole- $\mathrm{HCl}$, $\mathrm{pH} 8.0$ and $0.02 \%$ DDM. The protein was eluted from the affinity resin with wash buffer supplemented with $400 \mathrm{mM}$ imidazole- $\mathrm{HCl}, \mathrm{pH}$ 8.0. The proteins were concentrated to about $15 \mathrm{mg} / \mathrm{ml}$ before applying to gel-filtration chromatography (Superdex-200 10/30, GE Healthcare), which was equilibrated in the buffer containing $25 \mathrm{mM}$ Tris-HCl, pH 8.0, 150 
$\mathrm{mM} \mathrm{NaCl}$ and $0.4 \% n$-nonyl- $\beta$-D-glucopyranoside ( $\beta$-NG, Anatrace). The peak fractions of the protein $(\sim 8 \mathrm{gm} / \mathrm{ml})$ were collected and incubated with $0.1 \mathrm{mg} / \mathrm{ml}$ lipids

POPC:POPE:POPG (1-palmitoyl-2-oleoyl-sn-glycero-3-phosphocholine:1-palmitoyl-2oleoyl-sn-glycero-3-phosphoethanolamine:1-palmitoyl-2-oleoyl-sn-glycero-3-phospho-1glycerol, Anatrace) at mass ratio 3:1:1 for crystallization trials.

\section{Crystallization}

Crystals were grown at $18{ }^{\circ} \mathrm{C}$ by the hanging-drop vapor diffusion method. To improve resolution, multiple steps of construct modification, crystal growth optimization, and postcrystallization manipulation were explored. In the beginning, the C-terminal $\mathrm{His}_{6}$ tagged, WT proteins yielded cubic-shaped crystals in the buffer containing $0.7 \mathrm{M} \mathrm{MgSO}_{4}, 0.1 \mathrm{M}$ MES-NaOH, pH 6.0. The crystals diffracted to $\sim 8 \AA$ at BL41XU, Spring-8, Japan. Removal of His $_{6}$-tag improved the crystal quality significantly. Crystals of the WT, non-tagged protein appeared overnight in the buffer containing 16\% PEG 400 (v/v), $100 \mathrm{mM}$ MES$\mathrm{NaOH}, \mathrm{pH} 6.5,100 \mathrm{mM} \mathrm{CaCl}_{2}$, and diffracted to $4.0 \AA$ at the synchrotron radiation resource. However, it was difficult to scale the data sets to a specific space group. A single point mutation G208S improved the data quality. The space group was ultimately assigned as $P 4{ }_{1} 2{ }_{1} 2$ using the data sets obtained for $\mathrm{Na}_{\mathrm{v}} \mathrm{AP}-\mathrm{G} 208 \mathrm{~S}$. Further improvement was achieved with a new crystallization condition. Crystals appeared in the buffer containing 5\% PEG 8,000 (v/v), $100 \mathrm{mM}$ HEPES-NaOH, $\mathrm{pH} 7.0,100 \mathrm{mM} \mathrm{CaCl}_{2}, 10 \%$ Glycerol and 20\% 1,4Butandiol in $2 \mathrm{~d}$, and grew to $50 \mu \mathrm{m} \times 50 \mu \mathrm{m} \times 100 \mu \mathrm{m}$ tetragonal rods in $5 \mathrm{~d}$. The crystals, in the space group of $P 4_{2}$, were able to break the $4.0 \AA$ diffraction limit but with poor reproducibility and a high mosaicity value $(>5)$. Finally, the best crystals were obtained through dehydration manipulation, by gradually increasing the precipitant concentration in crystallization buffer to 15\% PEG 400 (v/v), 20\% PEG 8,000 (v/v). The crystals were flash frozen in liquid nitrogen, and diffracted beyond $3.05 \AA$ at SSRF (Shanghai Synchrotron Radiation Facility) beamline BL17U. Mercury derivatives were obtained by soaking the crystals for $3 \mathrm{~h}$ in the dehydration solution plus $10 \mathrm{mg} / \mathrm{ml}$ methylmercury chloride $\left(\mathrm{CH}_{3} \mathrm{HgCl}\right)$ as the final concentration.

\section{Data collection and processing}

All data sets were collected at the Shanghai Synchrotron Radiation Facility (SSRF) beamline BL17U, except for the native data in the space group of $P_{4}{ }_{1}{ }_{1} 2$, which were collected at the SPring- 8 beamline BL41XU. All were integrated and scaled with HKL2000 32 . Further processing was carried out using programs from the CCP4 suite ${ }^{33}$. Data collection statistics are summarized in Table S1.

\section{Experimental phasing and structure refinement}

The mercury positions in the $\mathrm{Hg}$-derived crystal of the $\mathrm{P}_{2}$ space group were determined using the program SHELXD ${ }^{34}$. The identified heavy-atom sites were refined and the initial phases were generated in the program PHASER ${ }^{35}$ with the SAD experimental phasing module. Cross-crystal averaging combined with solvent flattening, histogram matching and NCS averaging in DMMulti ${ }^{36}$ gave rise to electron density maps of sufficient quality for model building, using the data sets in Table S1. An initial model was built into the highresolution $\mathrm{P}_{2}$ native data using $\mathrm{COOT}^{37}$. The structure was refined with PHENIX ${ }^{38}$. All structure figures in the manuscript were prepared with $\mathrm{PyMol}^{39}$. The surface electrostatic potential presented in the manuscript was calculated with PyMol. The pore radii were calculated with the program "HOLE" 40 . 


\section{Electrophysiology}

Whole-cell voltage-clamp experiments were performed at $22^{\circ} \mathrm{C}$ in transiently transfected HEK-293 cells. Transfected cells were seeded onto glass coverslips and placed in a perfusion chamber for experiments in which extracellular conditions could be exchanged. Unless otherwise stated, the extracellular solution contained (in $\mathrm{mM}$ ): $\mathrm{NaCl} 150 ; \mathrm{CaCl}_{2} 1.5$; $\mathrm{MgCl}_{2}$ 1; glucose 10; and HEPES 10; $\mathrm{pH} 7.4$, and the intracellular (pipette) solution contained (in mM): $\mathrm{CsF} 105$; EGTA $10 ; \mathrm{NaCl} 35 ; \mathrm{MgCl}_{2}$ 4; and HEPES 10; $\mathrm{pH}$ 7.3. For experiments shown in the left panel of Figure 2c, representative current traces elicited by 0.5 -s depolarizations from $-140 \mathrm{mV}$ (holding potential) to $0 \mathrm{mV}$. $\mathrm{Na}^{+}$was substituted by the ions indicated $\left(150 \mathrm{Cs}^{+}, \mathrm{K}^{+} ; 110 \mathrm{Ca}^{2+}, \mathrm{Ba}^{2+}\right)$. Normalized current magnitudes plotted as a function of time as $\mathrm{Na}^{+}$-containing solution is exchanged for solutions with the indicated ions (colored boxes). For experiments shown in the right panel of Figure $2 \mathrm{c}$ and $2 \mathrm{~d}$, " \pm " indicates SEM.; $\mathrm{n}=4-5$ each. Current-voltage relationships were fit to $\left(\mathrm{V}-\mathrm{V}_{\mathrm{Rev}}\right) /\{1+$ $\left.\exp \left[\left(\mathrm{V}-\mathrm{V}_{1 / 2}\right) / \mathrm{k}\right]\right\}$, where $\mathrm{V}_{\operatorname{Rev}}$ is the extrapolated reversal potential, $\mathrm{V}_{1 / 2}$ is the halfactivation voltage, and $\mathrm{k}$ is a slope factor equal to $\mathrm{RT} / \mathrm{zF}$ ( $\mathrm{z}$ is the apparent gating charge, $\mathrm{R}$ the ideal gas constant, and F is Faraday's constant). Half-inactivation voltages were derived from fits to $1 /\left\{1+\exp \left(\mathrm{V}-\mathrm{V}_{1 / 2}\right) / \mathrm{k}\right\}$ to derive steady-state inactivation curves. Inactivating currents during $500 \mathrm{~ms}$ pulses were fit to $\mathrm{C}+\mathrm{A}\left(\mathrm{e}^{-\mathrm{t} / \tau}\right)$, where $\tau$ is the time constant, $\mathrm{A}$, the amplitude, and C, the baseline. For experiments shown in the left panel of Figure 2f, decay in response to a 500-ms pulse to the indicated potentials was fit to a single exponential. The half maximal inhibitory concentration $\left(\mathrm{IC}_{50}\right)$ was estimated by fitting the average percent of inward $\mathrm{Na}^{+}$blocked at each concentration to: \% block of the current amplitude $=1 /\{([\mathrm{D}] /$ $\left.\left.\mathrm{IC}_{50}\right)^{\mathrm{n}}+1\right\}$, where $\mathrm{n}$ is the Hill coefficient and [D] is the respective drug or divalent concentration.

\section{Animation}

In order to generate the morph to visualize the conformational change of the $\mathrm{S} 4$ segments between $\mathrm{Na}_{\mathrm{v}} \mathrm{AP}$ and $\mathrm{Na}_{\mathrm{v}} \mathrm{Ab}$, the homology-based model of $\mathrm{Na}_{\mathrm{v}} \mathrm{AP}$ was generated using the online SWISS-MODEL workspace ${ }^{41-43}$ with the structure of $\mathrm{Na}_{\mathrm{v}} \mathrm{Ab}$ (PDB code: $3 \mathrm{RVY}$, Chain A) as the model. The resulting structure was then superimposed on that of $\mathrm{Na}_{\mathrm{v}} \mathrm{AP}$ relative to the CTC. The shifted coordinates of the modeled structure and the original coordinates of $\mathrm{Na}_{\mathrm{v}} \mathrm{AP}$ were used as the initial and end states, respectively, for morph generation. The intermediate morphs were obtained with the multiple-chain morphing script $^{44,45}$ for Crystallography \& NMR System (CNS) ${ }^{46,47}$. The animations were finally produced using PyMol.

\section{Supplementary Material}

Refer to Web version on PubMed Central for supplementary material.

\section{Acknowledgments}

We thank R. MacKinnon at Rockefeller University for critical discussions and critical reading of the manuscript. We thank L. Feng at Rockefeller University for help. We thank S. Huang and F. Yu at Shanghai Synchrotron Radiation Facility (SSRF) beamline BL17U. K. Hasegawa acknowledges Spring-8 for proposal 2011A2039. This work was supported by funds from the Ministry of Science and Technology (grant numbers 2009CB918802, 2011CB910501, and 2011CB911102), Projects 31125009 and 91017011 of the National Natural Science Foundation of China, and funds from Tsinghua University.

\section{References}

1. Hille, B. Ion channels of excitable membranes. Sunderland, MA: Sinauer Associates; 2001. p. 814 
2. Mantegazza M, Curia G, Biagini G, Ragsdale DS, Avoli M. Voltage-gated sodium channels as therapeutic targets in epilepsy and other neurological disorders. Lancet Neurol. 2010; 9:413-424. [PubMed: 20298965]

3. Ren D, et al. A prokaryotic voltage-gated sodium channel. Science. 2001; 294:2372-2375. [PubMed: 11743207]

4. Payandeh J, Scheuer T, Zheng N, Catterall WA. The crystal structure of a voltage-gated sodium channel. Nature. 2011; 475:353-358. [PubMed: 21743477]

5. Catterall WA. The molecular basis of neuronal excitability. Science. 1984; 223:653-661. [PubMed: 6320365]

6. Jiang Y, et al. X-ray structure of a voltage-dependent K+ channel. Nature. 2003; 423:33-41. [PubMed: 12721618]

7. Long SB, Campbell EB, Mackinnon R. Voltage sensor of Kv1.2: structural basis of electromechanical coupling. Science. 2005; 309:903-908. [PubMed: 16002579]

8. Long SB, Tao X, Campbell EB, MacKinnon R. Atomic structure of a voltage-dependent K+ channel in a lipid membrane-like environment. Nature. 2007; 450:376-382. [PubMed: 18004376]

9. Butterwick JA, MacKinnon R. Solution structure and phospholipid interactions of the isolated voltage-sensor domain from KvAP. J Mol Biol. 2010; 403:591-606. [PubMed: 20851706]

10. Armstrong CM, Bezanilla F. Charge movement associated with the opening and closing of the activation gates of the Na channels. J Gen Physiol. 1974; 63:533-552. [PubMed: 4824995]

11. Aggarwal SK, MacKinnon R. Contribution of the S4 segment to gating charge in the Shaker K+ channel. Neuron. 1996; 16:1169-1177. [PubMed: 8663993]

12. Seoh SA, Sigg D, Papazian DM, Bezanilla F. Voltage-sensing residues in the S2 and S4 segments of the Shaker K+ channel. Neuron. 1996; 16:1159-1167. [PubMed: 8663992]

13. Vassilev PM, Scheuer T, Catterall WA. Identification of an intracellular peptide segment involved in sodium channel inactivation. Science. 1988; 241:1658-1661. [PubMed: 2458625]

14. Armstrong CM, Bezanilla F. Currents related to movement of the gating particles of the sodium channels. Nature. 1973; 242:459-461. [PubMed: 4700900]

15. Hoshi T, Zagotta WN, Aldrich RW. Biophysical and molecular mechanisms of Shaker potassium channel inactivation. Science. 1990; 250:533-538. [PubMed: 2122519]

16. Zagotta WN, Hoshi T, Aldrich RW. Restoration of inactivation in mutants of Shaker potassium channels by a peptide derived from ShB. Science. 1990; 250:568-571. [PubMed: 2122520]

17. Ulbricht W. Sodium channel inactivation: molecular determinants and modulation. Physiol Rev. 2005; 85:1271-1301. [PubMed: 16183913]

18. Todt H, Dudley SC Jr, Kyle JW, French RJ, Fozzard HA. Ultra-slow inactivation in mu1 Na+ channels is produced by a structural rearrangement of the outer vestibule. Biophys J. 1999; 76:1335-1345. [PubMed: 10049317]

19. Yellen G, Sodickson D, Chen TY, Jurman ME. An engineered cysteine in the external mouth of a $\mathrm{K}+$ channel allows inactivation to be modulated by metal binding. Biophys J. 1994; 66:10681075. [PubMed: 8038379]

20. Durell SR, Guy HR. A putative prokaryote voltage-gated $\mathrm{Ca}(2+)$ channel with only one 6TM motif per subunit. Biochem Biophys Res Commun. 2001; 281:741-746. [PubMed: 11237720]

21. Yue L, Navarro B, Ren D, Ramos A, Clapham DE. The cation selectivity filter of the bacterial sodium channel, NaChBac. J Gen Physiol. 2002; 120:845-853. [PubMed: 12451053]

22. Pavlov E, et al. The pore, not cytoplasmic domains, underlies inactivation in a prokaryotic sodium channel. Biophys J. 2005; 89:232-242. [PubMed: 15849254]

23. Harding MM. The geometry of metal-ligand interactions relevant to proteins. Acta Crystallogr D Biol Crystallogr. 1999; 55:1432-1443. [PubMed: 10417412]

24. Shannon RD. Revised effective ionic radii and systematic studies of interatomic distances in halides and chalcogenides. Acta Crystallographica Section A. 1976; 32:751-767.

25. Hille B. The hydration of sodium ions crossing the nerve membrane. Proc Natl Acad Sci U S A. 1971; 68:280-282. [PubMed: 5277069]

26. Armstrong CM, Cota G. Calcium ion as a cofactor in Na channel gating. Proc Natl Acad Sci U S A. 1991; 88:6528-6531. [PubMed: 1650473] 
27. Schmidt D, Cross SR, MacKinnon R. A gating model for the archeal voltage-dependent $\mathrm{K}(+)$ channel KvAP in DPhPC and POPE:POPG decane lipid bilayers. J Mol Biol. 2009; 390:902-912. [PubMed: 19481093]

28. Xiong W, Li RA, Tian Y, Tomaselli GF. Molecular motions of the outer ring of charge of the sodium channel: do they couple to slow inactivation? J Gen Physiol. 2003; 122:323-332. [PubMed: 12913092]

29. Tao X, Lee A, Limapichat W, Dougherty DA, MacKinnon R. A gating charge transfer center in voltage sensors. Science. 2010; 328:67-73. [PubMed: 20360102]

30. DeCaen PG, Yarov-Yarovoy V, Sharp EM, Scheuer T, Catterall WA. Sequential formation of ion pairs during activation of a sodium channel voltage sensor. Proc Natl Acad Sci U S A. 2009; 106:22498-22503. [PubMed: 20007787]

31. Sawaya MR, Pelletier H, Kumar A, Wilson SH, Kraut J. Crystal structure of rat DNA polymerase beta: evidence for a common polymerase mechanism. 1994; Vol. 264:1930-1935.

32. Otwinowski Z, Minor W. Processing of X-ray diffraction data collected in oscillation mode. Methods Enzymol. 1997; 276:307-326.

33. Collaborative Computational Project, N. The CCP4 suite: programs for protein crystallography. Acta Crystallogr. 1994; D50:760-763.

34. Schneider TR, Sheldrick GM. Substructure solution with SHELXD. Acta Crystallogr D Biol Crystallogr. 2002; 58:1772-1779. [PubMed: 12351820]

35. McCoy AJ, et al. Phaser crystallographic software. J. Appl. Crystallogr. 2007; 40:658-674. [PubMed: 19461840]

36. Cowtan K. dm: An automated procedure for phase improvement by density modification. Joint CCP4 and ESF-EACBM Newsletter on Protein Crystallogr. 1994; 31:34-38.

37. Emsley P, Cowtan K. Coot: model-building tools for molecular graphics. Acta Crystallogr. D. 2004; 60:2126-2132. [PubMed: 15572765]

38. Adams PD, et al. PHENIX: building new software for automated crystallographic structure determination. Acta Crystallogr. 2002; D58:1948-1954.

39. DeLano WL. The PyMOL Molecular Graphics System. on World Wide Web. 2002 http:// www.pymol.org.

40. Smart OS, Goodfellow JM, Wallace BA. The pore dimensions of gramicidin A. Biophys J. 1993; 65:2455-2460. [PubMed: 7508762]

41. Arnold K, Bordoli L, Kopp J, Schwede T. The SWISS-MODEL workspace: a web-based environment for protein structure homology modelling. Bioinformatics. 2006; 22:195-201. [PubMed: 16301204]

42. Schwede T, Kopp J, Guex N, Peitsch MC. SWISS-MODEL: An automated protein homologymodeling server. Nucleic Acids Res. 2003; 31:3381-3385. [PubMed: 12824332]

43. Guex N, Peitsch MC. SWISS-MODEL and the Swiss-PdbViewer: an environment for comparative protein modeling. Electrophoresis. 1997; 18:2714-2723. [PubMed: 9504803]

44. Echols N, Milburn D, Gerstein M. MolMovDB: analysis and visualization of conformational change and structural flexibility. Nucleic Acids Res. 2003; 31:478-482. [PubMed: 12520056]

45. Krebs WG, Gerstein M. The morph server: a standardized system for analyzing and visualizing macromolecular motions in a database framework. Nucleic Acids Res. 2000; 28:1665-1675. [PubMed: 10734184]

46. Brunger AT, et al. Crystallography \& NMR system: A new software suite for macromolecular structure determination. Acta Crystallogr D Biol Crystallogr. 1998; 54:905-921. [PubMed: 9757107]

47. Brunger AT. Version 1.2 of the Crystallography and NMR system. Nat Protoc. 2007; 2:27282733. [PubMed: 18007608] 
a

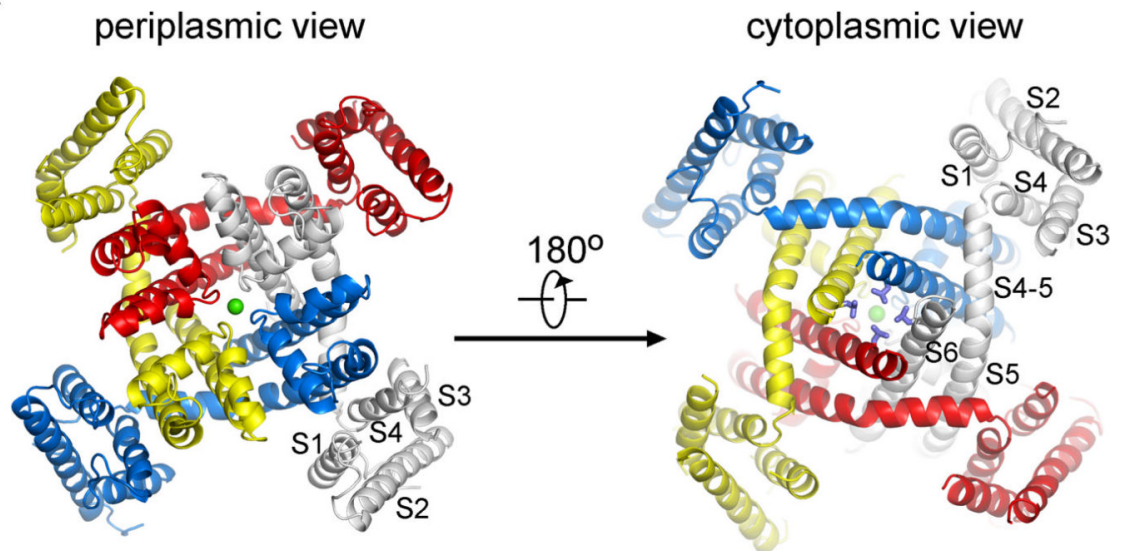

b

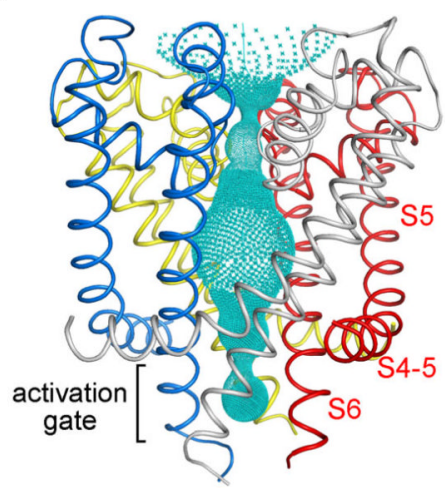

C
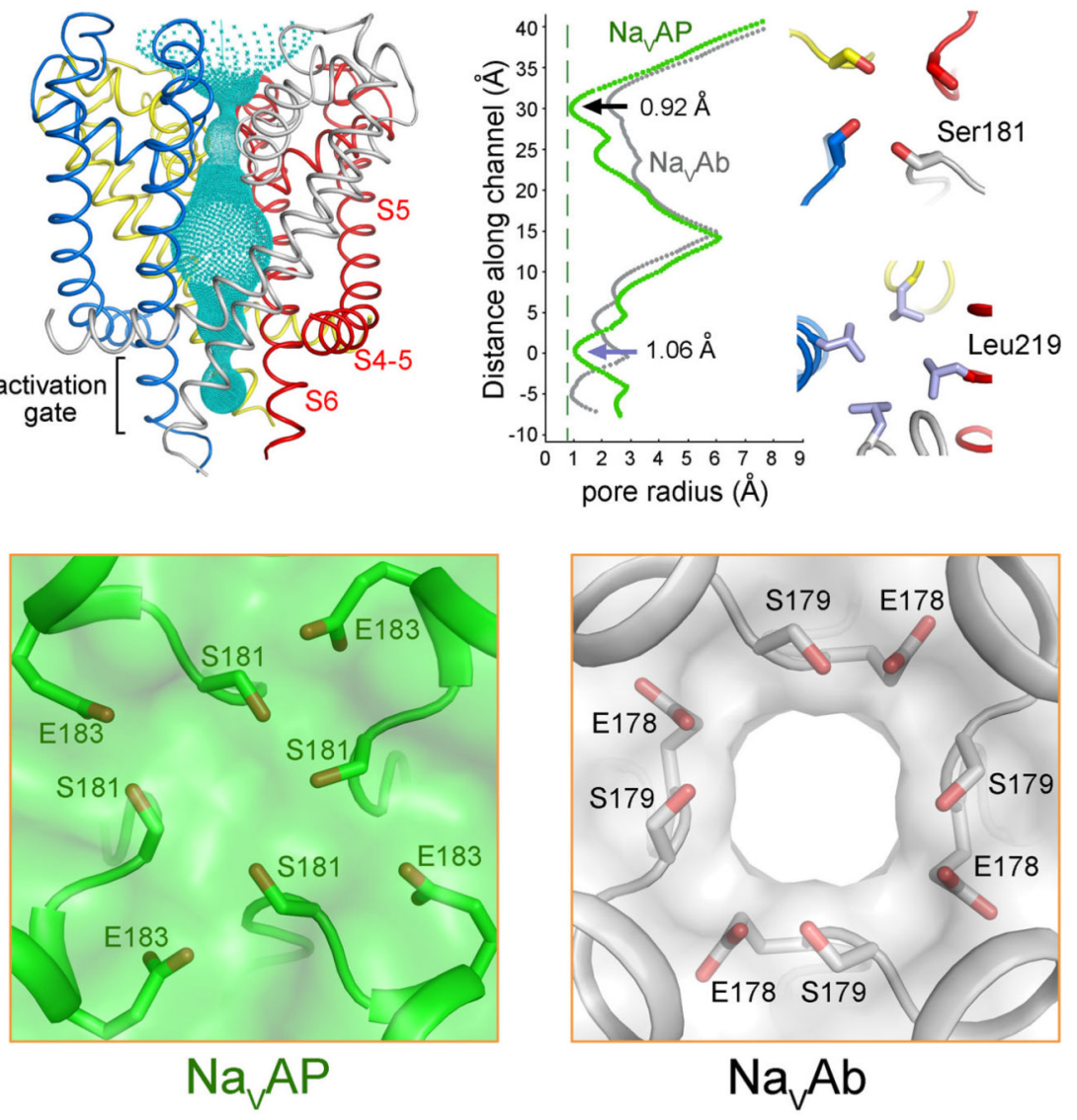

Fig. 1. The structure of $\mathrm{Na}_{\mathrm{v}} \mathrm{AP}$ exhibits a closed conformation

(a) $\mathrm{Na}_{\mathrm{v}} \mathrm{AP}$ exhibits an asymmetric tetramer in the structure. The green sphere indicates the bound ion within the selectivity filter. Leu219, which occludes the activation gate, is shown in light purple sticks in the cytoplasmic view. (b) $\mathrm{Na}_{\mathrm{v}} \mathrm{AP}$ is closed at both the activation gate and the entrance to the selectivity filter. The channel passage (left panel) is indicated by cyan dots. The pore radii (right panel) of $\mathrm{Na}_{\mathrm{v}} \mathrm{AP}$ (green) are compared with those of $\mathrm{Na}_{\mathrm{v}} \mathrm{Ab}$ (grey). The residues that constitute the constriction sites, Ser181 at the entrance to the selectivity filter and Leu219 at the activation gate, are shown in sticks in periplasmic and 
cytoplasmic views, respectively. (c) A semi-transparent surface illustration of the periplasmic entrance to the selectivity filter in $\mathrm{Na}_{\mathrm{v}} \mathrm{AP}$ and $\mathrm{Na}_{\mathrm{v}} \mathrm{Ab}$. 
a

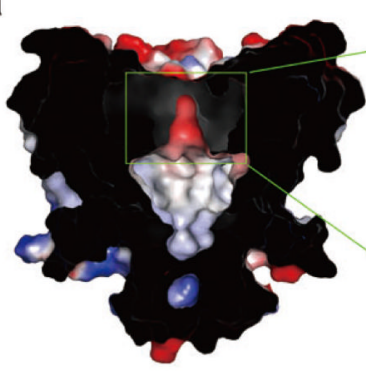

C

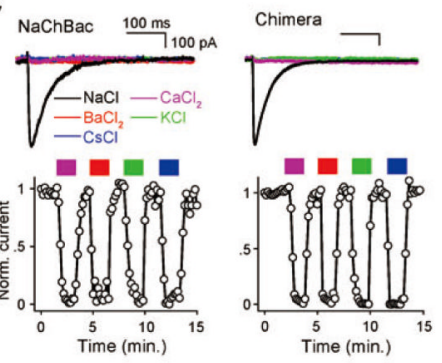

e

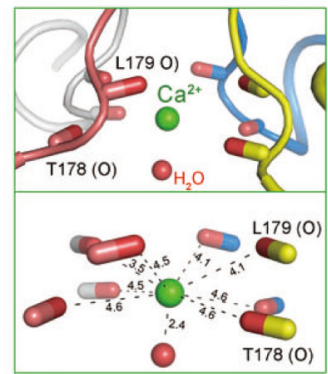

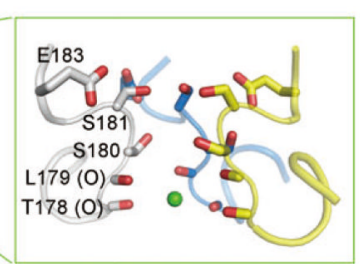

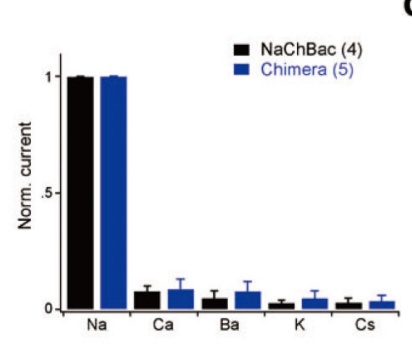

b
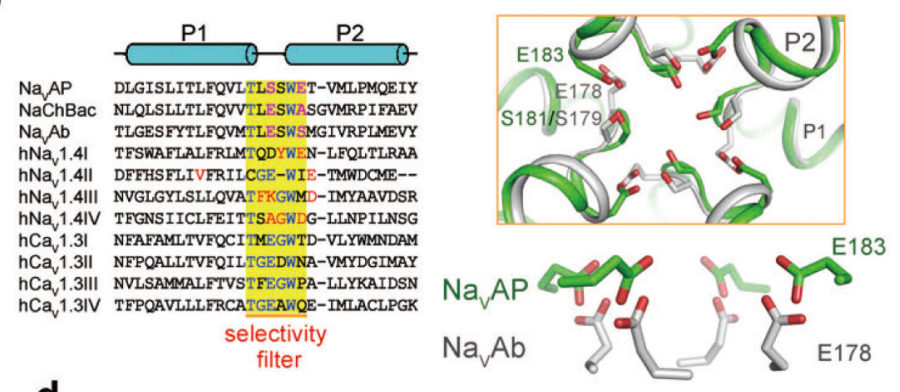

d
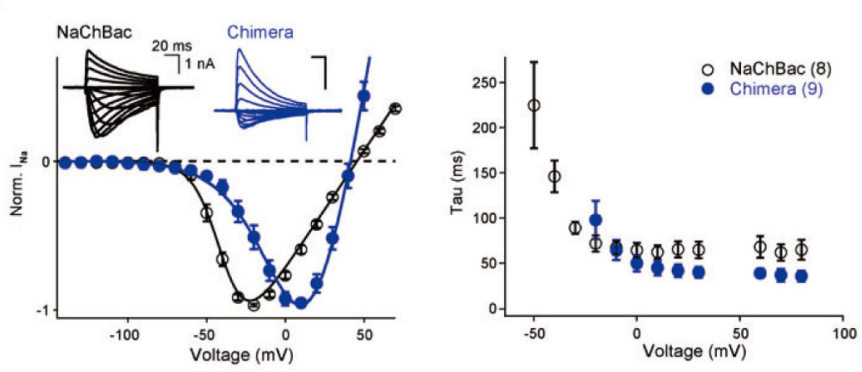

f
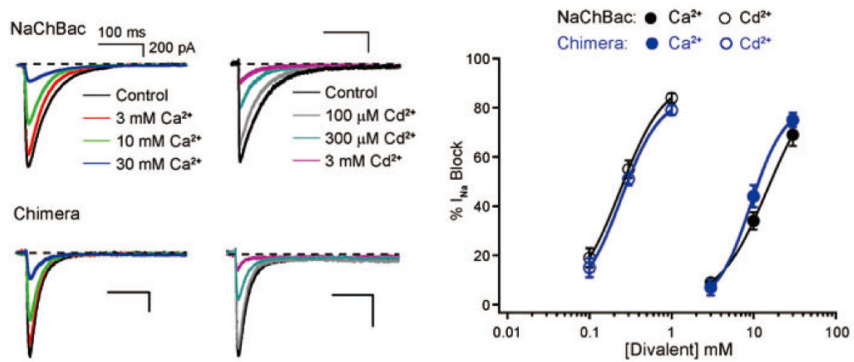

Fig. 2. $\mathrm{A} \mathrm{Ca}^{2+}$ ion is bound in the asymmetric selectivity filter of $\mathrm{Na}_{\mathrm{v}} \mathrm{AP}$

(a) A side view of the selectivity filter vestibule of NavAP. (b) The carboxylate groups of $\mathrm{Na}_{\mathrm{v}} \mathrm{AP}-\mathrm{E} 183$ and $\mathrm{Na}_{\mathrm{v}} \mathrm{Ab}$-E178 are positioned similarly in spite of their distinct Ca locations within the selectivity filter. The residues that are important for slow inactivation of $\mathrm{Na}_{\mathrm{v}} 1.4$ are colored red in the sequence alignment. (c) The $\mathrm{Na}_{\mathrm{v}} \mathrm{AP}$ selectivity filter is sodiumselective. (d) Current-voltage relationships for $\mathrm{NaChBac}$ and the $\mathrm{NaChBac} / \mathrm{Na}_{\mathrm{v}} \mathrm{AP}$-filter chimera, and rates of inactivation (tau, $\tau$ ) of $\mathrm{I}_{\mathrm{Na}}$. $\left(\right.$ e) $\mathrm{A} \mathrm{Ca}^{2+}$ ion is bound at an inner site within the selectivity filter. The distances between the ion and the surrounding groups are indicated in angstroms ( $⿱$ ) $)$. (f) Progressive reduction in $\mathrm{I}_{\mathrm{Na}}$ by the addition of $\mathrm{Ca}^{2+} \mathrm{or} \mathrm{Cd}^{2+}$. The potency of $\mathrm{I}_{\mathrm{Na}}$ block was estimated (right; see Methods). 
a

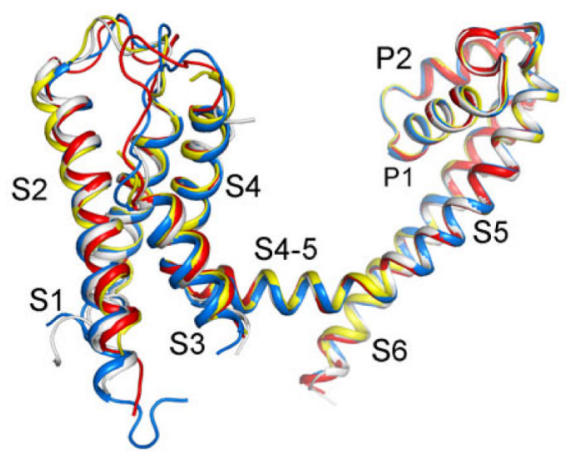

b

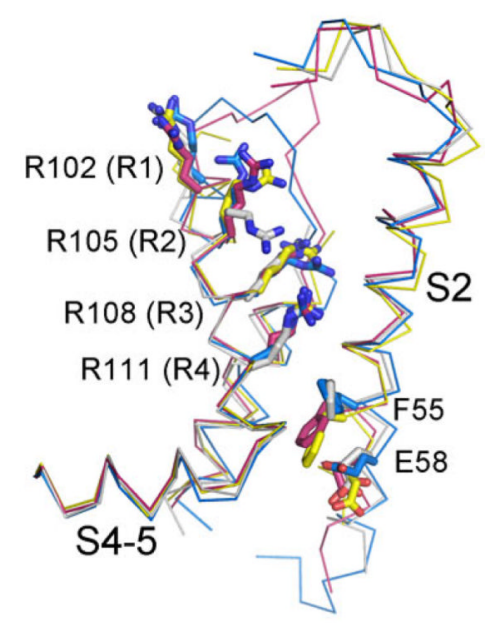

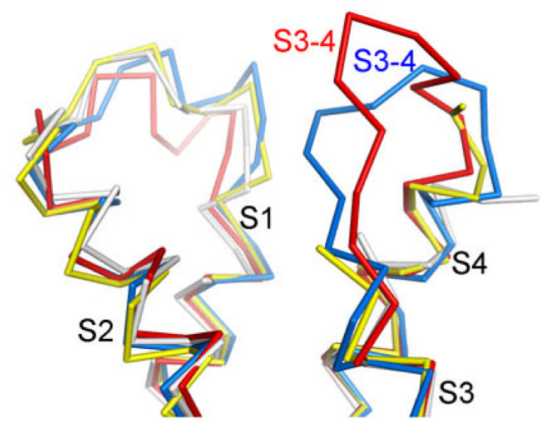

C

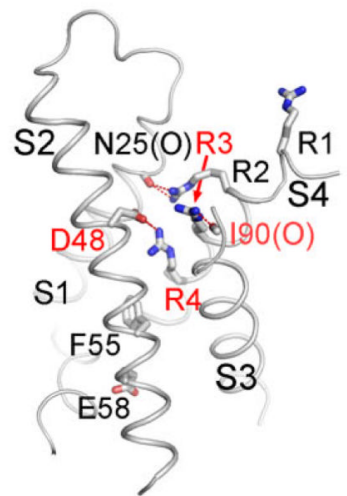

Mol A

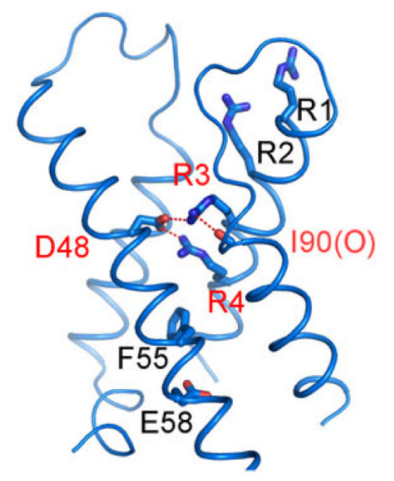

Mol B
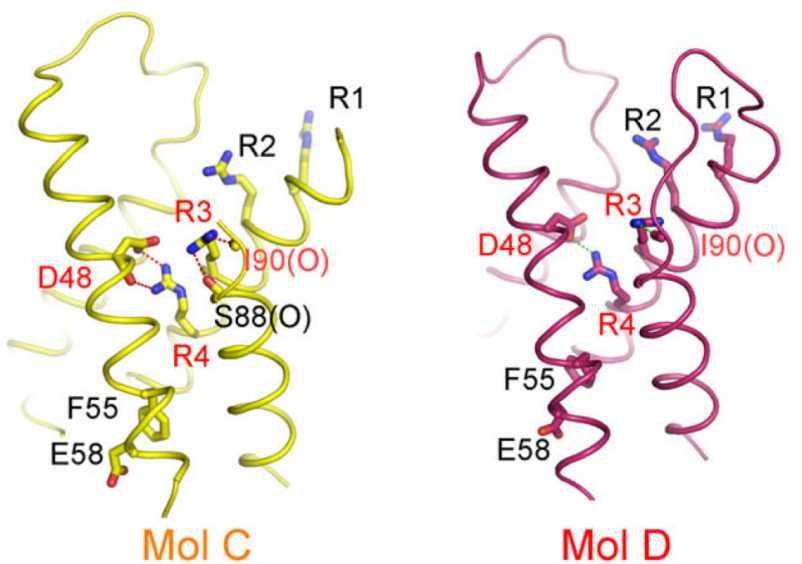

Fig. 3. The VSDs of $\mathrm{Na}_{\mathbf{v}} \mathrm{AP}$ exhibit a depolarized conformation

(a) Superimposition of the four protomers in $\mathrm{Na}_{\mathrm{v}} \mathrm{AP}$ structure. An enlarged view of S3-S4 linkers is shown on the right to highlight their conformational distinctions. (b) The S1 to S4 segments of the four VSDs exhibit similar conformations with all the gating charges pointing to the extracellular surface. The gating charges (R1-R4) on the S4 segment, as well as Phe55 and Glu58 on the S2 segment, are shown as sticks. (c) The coordination of the gating charges in the four VSDs of $\mathrm{Na}_{\mathrm{v}} \mathrm{AP}$. Hydrogen bonds are represented by red (Mol AC) or green $(\mathrm{Mol} \mathrm{D})$ dashed lines. The residues that mediate invariant interactions between gating charges and the external-negative cluster are labeled in red. 
a

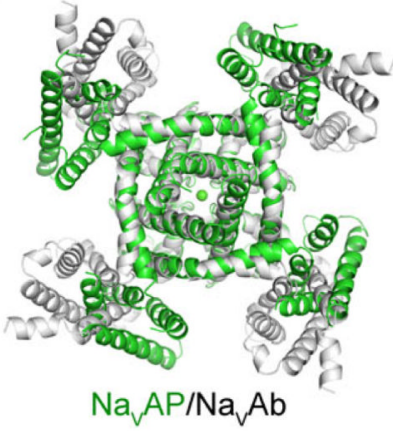

C

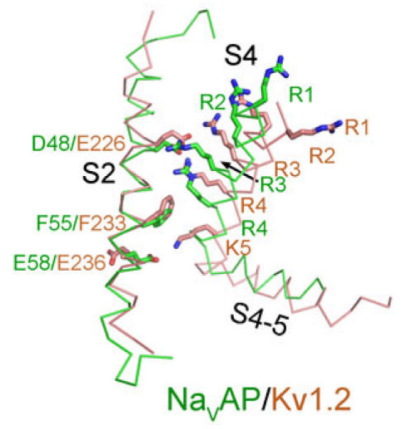

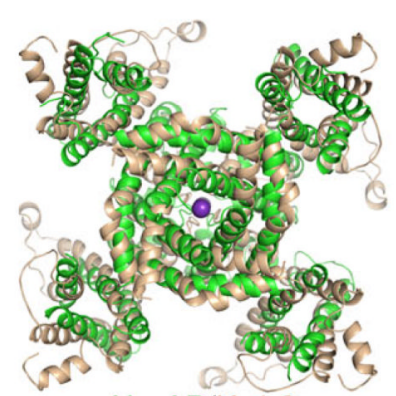

$\mathrm{Na}_{\mathrm{V}} \mathrm{AP} / \mathrm{Kv} 1.2$

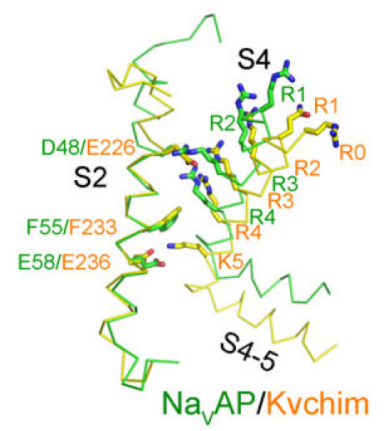

b

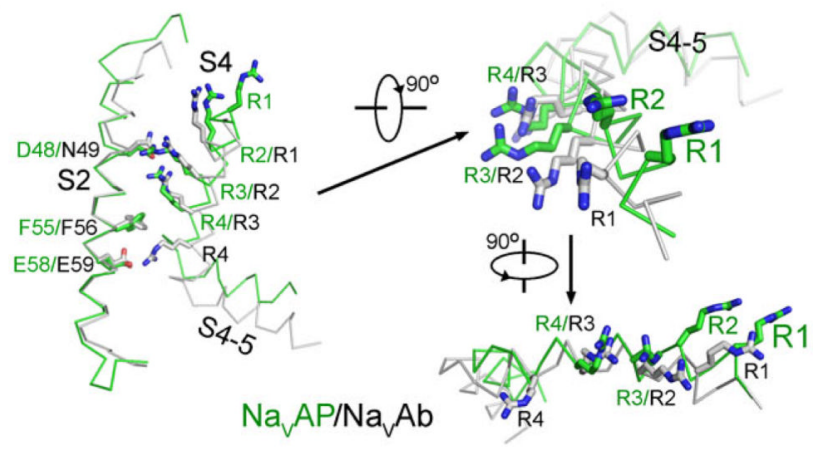

d

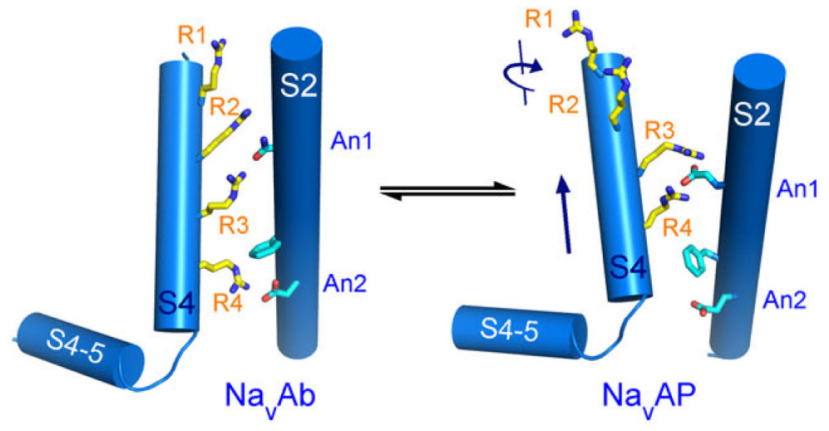

Fig. 4. Molecular basis of charge transfer of VSDs

(a) Superimposition of the structures of $\mathrm{Na}_{\mathrm{v}} \mathrm{AP}$ (green), $\mathrm{Na}_{\mathrm{v}} \mathrm{Ab}$ (grey), and Kv1.2 (brown), relative to the pore domains. Cytoplasmic views are shown. $\mathrm{Ca}^{2+}$ and $\mathrm{K}^{+}$are shown in green and purple spheres. (b) There is a one helical turn shift toward the extracellular side of $\mathrm{Na}_{\mathrm{v}} \mathrm{AP}-\mathrm{S} 4$ compared to $\mathrm{Na}_{\mathrm{v}} \mathrm{Ab}$-S4 when the charge transfer centers (CTC) are superimposed. Note that the segment of $\mathrm{Na}_{\mathrm{v}} \mathrm{AP}-\mathrm{S} 4$ containing R1 and R2 is an a-helix, whereas the corresponding segment of $\mathrm{Na}_{\mathrm{v}} \mathrm{Ab}-\mathrm{S} 4$ is still a $310^{\text {-helix. (c) Structural }}$ comparison of the $\mathrm{S} 4$ segments from $\mathrm{Na}_{\mathrm{v}} \mathrm{AP}, \mathrm{Kv} 1.2$, and the paddle chimera. These structures are superimposed against the CTC. (d) A schematic illustration of the process of one charge (R4) transfer across the occluding residue, Phe, within the CTC. A structurebased animation is shown in Supplementary movie S1. 